Disaggregated Indian Industrial Cycles: A spectral analysis

Ritabrata Bose and Ashima Goyal

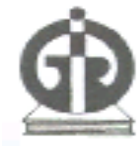

Indira Gandhi Institute of Development Research, Mumbai October 2020 


\title{
Disaggregated Indian Industrial Cycles: A spectral analysis
}

\author{
Ritabrata Bose and Ashima Goyal
}

Email(corresponding author): ashima@igidr.ac.in

\begin{abstract}
We study the structure and dating of disaggregated Indian industrial cycles and spectral causality from different policy parameters to these cycles. The scattered pattern of peaks and troughs after 2013, suggests some industries continued to do well during an extended slowdown. Post 2011 industrial cycles have been shallow and short. The exchange rate, currency, credit, nominal and real interest rates all affect industry cycles, but differences in impact by industry type may be due to the structure of the economy. Cash and credit are more important for consumer non-durables, while interest rates affect consumer durables and capital goods. Interest rates do matter but in combination with currency and credit. Co-movement across disaggregated industry points to some common drivers. Stabilization policies need to be used more and fine-tuned based on research. Results on the dating and duration of industry cycles, their cyclicality, phase shifts, amplitude, lead-lag sectors, duration asymmetry and co-movement can help design appropriate policies.
\end{abstract}

Keywords: Industrial cycles, co-movement, coherence, lead/lag, business cycle dating, spectral causality, macroeconomic stabilization.

JEL Code: E23, E32, C32. 


\section{Disaggregated Indian Industrial Cycles: A spectral analysis}

\section{Introduction}

Since the implementation of economic reforms of the 1990s, India, an emerging market economy, has experienced fast-paced growth; its real gross domestic product (GDP) has increased more than 300\% from 1990 to 2017, with an average annual growth rate of about 6\%. However, the scenario of industrial production was more complicated - the quarterly data of the index of industrial productivity (IIP) showed an average of about $7 \%$ growth till 2010, while it plummeted to an average of about $3 \%$ from 2011 to 2019. Since 2011, India faced a prolonged industrial slowdown.

Although there has been a great deal of empirical work on Indian business cycles (Pandey et. al., 2019, 2017; Dua and Banerji, 2012; Nandi, 2011), most studies have focused on the correlations between business cycles and aggregate IIP series, as far as industrial productivity is concerned. In contrast, little is known about the structure and dating of productivity cycles of disaggregated industries, and the idiosyncratic effect of policy parameters on different group of industries. The concentration of cyclical phases is a cornerstone of the classical definition of cyclical co-movement (as suggested by Burns and Mitchell, 1946), but very little is known about the co-movement of phase shifts across Indian industries - which carries important information regarding developments of economic activity across industries. A better understanding of the phase shifts in India's disaggregated industrial production cycles is particularly useful for policymakers and government officials, not only in devising target policies to attenuate the economic effect of cyclical fluctuations, but also for promoting growth in targeted industries.

A handful of studies have investigated the phase shifts in business cycles like Harding and Pagan, 2006, Chauvet and Piger, 2008, Stock and Watson, 2014, Iacoviello, 2015, Mian et. al., 2017, and Bloom et. al., 2018. Despite being one of the largest and one of the most significant emerging countries in the world, however, the phase shifts in India's industries have not been studied ${ }^{1}$. Considering the asymmetry of phase shifts, a growing body of literature has explored causality in frequency domain, which unearths causality between two or more variables across different frequencies, including studies by Assenmacher-Wesche and Gerlach (2007, 2008a, b); Gronwald (2009); Tiwari (2012a, b); and Wei (2014). However, to the best of our knowledge, none of the studies have analysed the causality of policy parameters on industrial production cycles.

The analysis of the empirical pattern of cyclical industrial dynamics, or industrial cycles as they are commonly known, forms the basis of modern business cycle models (Chang and Hwang, 2015). The industrial cycles continue to behave in ways described by Schumpeter in his seminal work (1912, 1934), with the troughs (upturns) creating an opportunity for profit and peaks (downturns)

\footnotetext{
${ }^{1}$ On 2017, India's share of world GDP was around 3\%, making it the fifth highest in the world.
} 
creating an opportunity for restructuring (Tan and Mathews 2009). These dynamics have caused the issue of cycles to enter key debates, primarily concerning the timing of innovation and investment. In another strand, it has also been argued in the literature (starting from Mankiw and Reis, 2003), that in an inflation-targeting regime, the weight of a sector in the stability price index depends on the sector's characteristics like cyclical patterns, co-movement and, phase shifts. Following the undertaking of inflation targeting by the Reserve Bank of India (India's central bank), our results can be used for such analysis.

In this paper, we take a step toward filling the above gaps. More specifically, we provide empirical evidence on - (1) the structure and dating of disaggregated Indian industrial cycles and (2) spectral causality from different policy parameters to these cycles. Using a panel of IIP use-based data, we find that the average duration of cycles is longer during expansions than during recessions, and this asymmetry is highest for basic industries. Consumer durables show most frequent phase shifts, while for the aggregate industry, it is very low. Amplitude is highest for capital goods industries, much above the aggregate. High amplitude is found with low duration asymmetry. It is also observed that the co-movement across phase shifts is high and is more significant during troughs so that a broad-based upturn is possible with the correct policies. Phase shifts tend to coincide across industries, but the concentration is higher during recessions compared to expansions. There is more persistence of the same industry in consecutive peaks than in troughs. Bi-directional causality exists between industry types and monetary policy variables. The exchange rate, currency, credit, nominal and real interest rates all affect industry cycles, but differences in impact by industry type may be due to the structure of the economy. Cash and credit are more critical for consumer non-durables, while interest rates matter for consumer durables and capital goods. Basic goods are somewhat insulated, except for working capital, perhaps because of more government ownership. Real interest rates weakly affect basic goods and intermediates.

From Figure 1, we observe cycles for different sectors (based on usage) are quite distinctive. For robustness, we have used two types of filters to extract cycles from the deseasonalized ${ }^{2}$ data - the Hodrick Prescott (HP) filter (1997) and the bandpass filter proposed by Christiano and Fitzgerald (CF) (2003). It has been observed that although for annual series, there is a deviation of HP filter from band-pass filters like CF and Baxter-King $(B K)^{3}$ (1999), for quarterly series these filters yield similar cycles. Although HP filter does not amplify high-frequency noise, it allows much of the highfrequency noise to be left outside the business cycle frequency band. This has been complemented by the low pass band-pass filter (in our case, CF filter) which has the downside of underestimating the

\footnotetext{
${ }^{2}$ We have used Census X-13 ARIMA-SEATS seasonal adjustment program to filter out the seasonal components.

${ }^{3}$ Due to shorter data time span, BK filter will not be appropriate as it leads to data loss in the terminal quarters.
} 
cyclical component. We follow Rand and Tarp $(2002)^{4}$ and employ both HP filter and CF filter to extract cycles.

\section{Comparison of different industries (based on usage)}
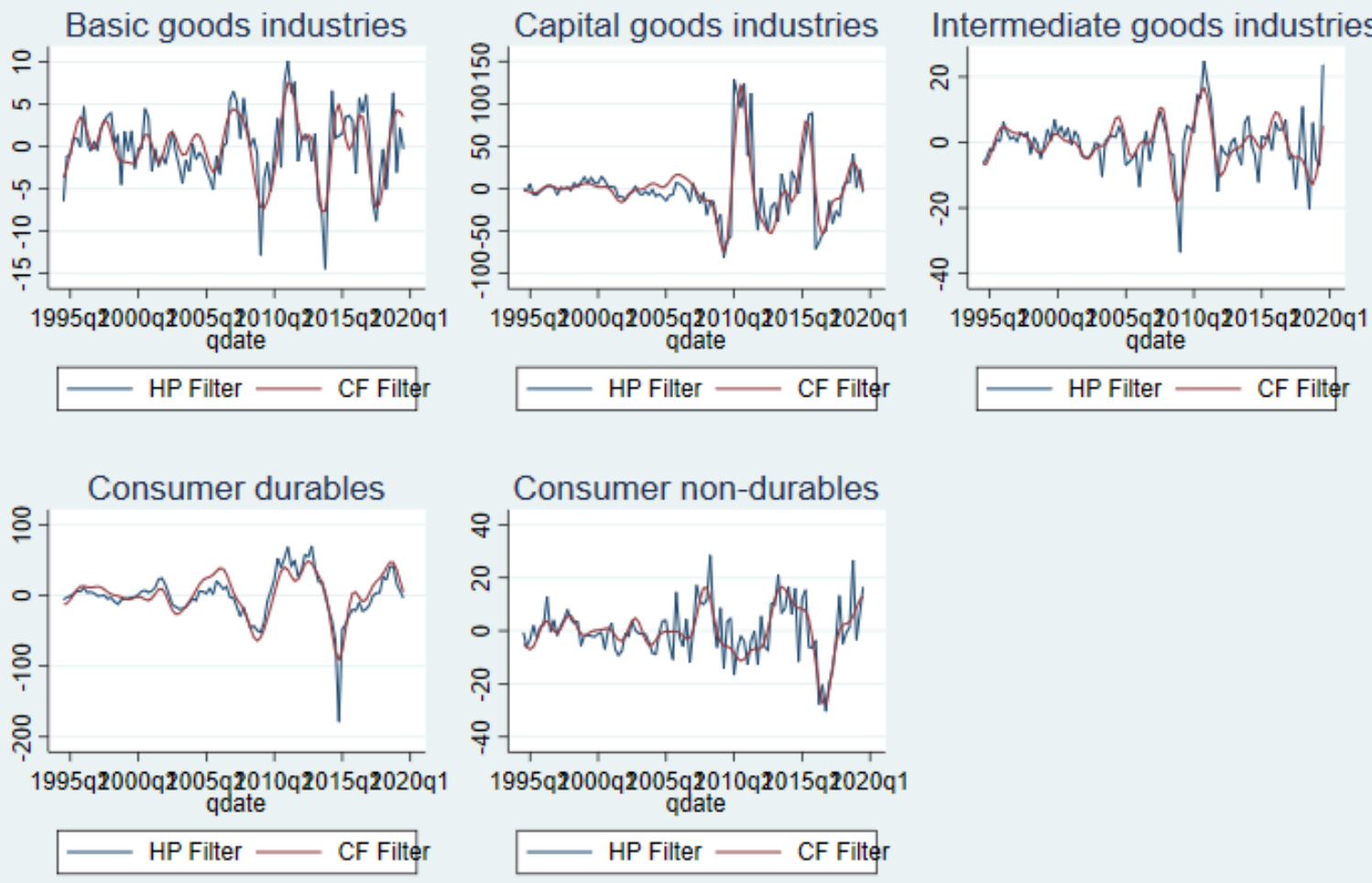

Figure 1: Industrial cycles (Hodrick Prescott Filter and Christiano Fitzgerald filter)

We believe our paper contributes to two strands of literature - the Indian business cycle literature (Pandey et al. 2017; Dua and Banerji 2012) and the macroeconomic study of industries (Chang and Hwang 2015; Foerster, Sarte and Watson 2011; Tan and Mathews 2009). Business cycles are somewhat neglected in India (along with other emerging economies ${ }^{5}$ ) with an emphasis on structural reform. Being the first study of industrial cycles of India, our paper will give an additional dimension to the literature, by unearthing the patterns and synchronicity of sectoral cycles and will motivate business cycles theories to incorporate the sectoral patterns for India. It will also serve policymakers by informing them about the patterns of a specific sector concerning a change in parameters and enable more informed stabilization policies. Our paper will give critical insights on the patterns of sectoral cycles for analysts interested in predictions for a newly liberalized, globalised and privatized developing economy, where market forces are slowly coming into play.

\footnotetext{
${ }^{4}$ Rand and Tarp (2002) have used HP filter and BK filter.

${ }^{5}$ We could only find only one other study, on China, by Kong et. al. (2019).
} 
The rest of the paper has been arranged as follows: Section 2 outlines the theoretical underpinnings. Section 3 explains the data and variables. Results of our study have been placed in section 4, while section 5 concludes our study.

\section{Methodology}

\subsection{Industrial cycles dating}

We identified turning points of individual industrial cycles by applying the algorithm proposed by Harding and Pagan (2002) to the IIP series cycles (generated by HP filter). We use this algorithm since it does not depend on any particular definition of trend components from the raw series, which in turn avoids potential problems inherent in de-trending methods. Due to the extensive usage of this algorithm in the literature, it is comparable with other studies.

Implementation of Harding and Pagan (2002) (a quarterly variant of the Bry and Boschan (1971) algorithm) involves the following stages:

1. A peak is defined in a time series $\left\{y_{t}\right\}_{t=1}^{T}$ as occurring at time $t$ if $y_{t}=\max \left\{y_{t-2}, y_{t-1}, y_{t}, y_{t+1}, y_{t+2}\right\}$ and a trough is defined as occurring at time $t$ if $y_{t}=\min \left\{y_{t-2}, y_{t-1}, y_{t}, y_{t+1}, y_{t+2}\right\}$.

2. Check whether these peaks and troughs satisfy predetermined 'censoring rules' as described below.

Censoring rules: (i) peaks and troughs occur alternately, and that (ii) a phase and a complete cycle have minimum durations. If these requirements are not fulfilled, the least pronounced among adjacent turning points is eliminated. In this paper, we set the minimum duration of a phase to be 2 quarters and that of a cycle to be 5 quarters.

After finding out the peaks and troughs of the industrial cycles ${ }^{6}$, we have computed various summary statistics to give an idea of the cyclical characteristics of the industries, namely, cyclical durations, duration of asymmetry, number of recession and expansion cycles and amplitude - across both the phases (expansionary phase and recessionary phase). Duration asymmetry is defined as how long/short the expansionary cycles with respect to recessionary cycles and is measured by the ratio of the average duration of expansion to that of recession. The amplitude of the expansion and the recession phases of the business cycles is a measure of the extent that economic activity changes during the phase.

\footnotetext{
${ }^{6}$ Here, we have used the IIP use-based series for tractability.
} 


\subsection{Co-movement indices}

Following Harding and Pagan (2002), Artis et. al. (2004) and Chang and Hwang (2015), the degree of concentration of co-movement between two industrial cycles can be measured using concordance and diffusion indices.

The concordance index measures the proportion of time the two cycles are in the same phase, and it is used in two different ways - pairwise concordance indices between industries and concordance of individual industries with the aggregate IIP. The concordance index is measured by,

$$
\text { Concordance }_{i, j}=\frac{1}{T} \sum_{t=1}^{T}\left[C_{i t} C_{j t}+\left(1-C_{i t}\right)\left(1-C_{j t}\right)\right]
$$

where $C_{i t}$ and $C_{j t}$ are binary variables indicating contractions of industries $i$ and $j$ respectively ${ }^{7}$. Here, $j$ can be other industries or aggregate IIP.

Another measure of comovement, the diffusion index measures the proportion of industries sharing the same phase at a point in time. Diffusion index for contraction is measured by,

$$
\text { Diffusion }_{t}=\sum_{i=1}^{N} w_{i t} C_{i t}, \sum_{i=1}^{N} w_{i t}=1 \forall t=1, \ldots, T
$$

where $w_{i t}$ is the weights for each industry and in this paper, we have used equal weights for all the industries.

\subsection{Distribution of turning points}

To determine the leading, lagging and coincident industries, with respect to the aggregate IIP series, we employ the dynamic correlation (using autocovariance function) and note down the lags in which the two series have the highest correlation.

In this section, we also calculate transition probabilities $\left(\tau_{i j}\right)$ for IIP peak to peak transition and trough to trough transition separately. It measures the average probability of industries moving into $j^{\text {th }}$ group (leading, lagging, coincident or acyclical) among the industries that were present in the $i^{\text {th }}$ group between two adjacent aggregate IIP peaks and between two adjacent aggregate IIP troughs.

Last, we calculate the concentration of turning points asymmetry, to find whether the distributions of IIP sectoral turning points have the same concentration between aggregate IIP peaks and troughs. We define a turning point cluster whose distance from the given aggregate IIP turning

\footnotetext{
${ }^{7} C_{i t}=1$ if industry $i$ is in a contractionary phase and $C_{i t}=0$, otherwise.
} 
point is less than 8 quarters (Harding and Pagan 2006). Let $\Lambda_{i j}^{P}$ be the $j^{\text {th }}$ peak of industry $i$ and $m_{k}$ be the $k^{\text {th }}$ peak in the aggregate IIP cycle. Then, the $k^{\text {th }}$ peak cluster centered around $m_{k}$ is,

$$
\sigma_{k}=\left\{\Lambda_{i j}^{P} \mid d\left(m_{k}-\Lambda_{i j}^{P}\right)<d\left(m_{l}-\Lambda_{i j}^{P}\right) \forall l \neq k \text { and } d\left(m_{k}-\Lambda_{i j}^{P}\right) \leq 8\right\}
$$

\subsection{Causality (frequency domain)}

Here we employ the notion of causality as introduced by the seminal work of Granger (1969, 1980). The basic idea being, a variable, say $X_{t}$ is said to cause another variable, say $Y_{t}$, if $X_{t}$ contains information about future $Y_{t}$ that is not contained in the information set, consisting of past $Y_{t}$. The methodology proposed by Granger (1969) has been used in numerous studies spreading across different fields. The conventional causality tests are conducted as Wald tests in Vector Autoregression (VAR) models, which produce a single, one-shot statistic regarding predictability while implicitly ignoring the possibility of causal dynamics across different frequencies (Ciner 2011a). Granger and Lin (1995) showed that the extent and the direction of causality could differ between frequency bands. It will be useful for us to provide short-term spillovers versus long-term causal relations between the policy parameters and the industries, which can be accomplished by examining the test statistic across the full spectra.

Causality in the frequency domain have been proposed by Geweke (1982) and Hosoya (1991); however, due to nonlinearities, the test statistics in the frequency domain has been found difficult to estimate. By building on the earlier works of Geweke (1982), Breitung and Candelon (2006) have shown test statistics can be calculated by imposing linear restrictions on the autoregressive (AR) parameters in the VAR model. They have also found that their methodology has good size properties in Monte Carlo experiments and Lemmens et al. (2008) concluded that the approach was the most efficient among the ones considered.

Geweke (1982) considers two-dimensional vector, say $X_{t}$ and $Y_{t}$ with a finite order VAR (p):

$$
\theta(L)\left[\begin{array}{l}
Y_{t} \\
X_{t}
\end{array}\right]=\left[\begin{array}{ll}
\theta_{11}(L) & \theta_{12}(L) \\
\theta_{21}(L) & \theta_{22}(L)
\end{array}\right]\left[\begin{array}{l}
Y_{t} \\
X_{t}
\end{array}\right]=\epsilon_{t}
$$

where $\theta(L)=I-\theta_{l} L-\cdots-\theta_{p} L_{p}$ is a $2 \times 2$ lag polynomial and $\theta_{l}, \ldots, \theta_{p}$ are $2 \times 2$ autoregressive parameter matrices, with $L^{k} X_{t}=X_{t-k}$ and $L^{k} Y_{t}=Y_{t-k}$. The error vector $\epsilon_{t}$ is white noise with zero mean and $E\left(\epsilon_{t}, \epsilon_{t}^{\prime}\right)=\Sigma$, where $\Sigma$ is positive definite. The MA representation of the system is given by,

$$
\left[\begin{array}{l}
Y_{t} \\
X_{t}
\end{array}\right]=\Psi(L) \eta_{t}=\left[\begin{array}{ll}
\Psi_{11}(L) & \Psi_{12}(L) \\
\Psi_{21}(L) & \Psi_{22}(L)
\end{array}\right]\left[\begin{array}{l}
\eta_{1 t} \\
\eta_{2 t}
\end{array}\right]
$$

with $\Psi(L)=\theta(L)^{-1} G^{-1}$ and $G$ is the lower triangular matrix of the Cholesky decomposition. 
$G^{\prime} G=\Sigma^{-1}$, such that $E\left(\eta_{t} \eta_{t}^{\prime}\right)=I$ and $\eta_{t}=G \epsilon_{t}$. The causality test developed by Geweke (1982) which measures linear feedback from $X_{t}$ to $Y_{t}$ at frequency, $\omega$ can thus be written as:

$$
M_{X \Rightarrow Y}(\omega)=\log \left[1+\frac{\left|\Psi_{12}\left(e^{-i \omega}\right)\right|^{2}}{\left|\Psi_{11}\left(e^{-i \omega}\right)\right|^{2}}\right]
$$

when $\left|\Psi_{12}\left(e^{-i \omega}\right)\right|=0, X_{t}$ does not Granger cause $Y_{t}$ at frequency $\omega$. Breitung and Candelon (2006) have showed that this condition leads to

$$
\left|\theta_{12}\left(e^{-i \omega}\right)\right|=\left|\sum_{k=1}^{p} \theta_{k, 12} \cos (k \omega)-i \sum_{k=1}^{p} \theta_{k, 12} \sin (k \omega)\right|=0
$$

with $\theta_{k, 12}$ being the $(1,2)$ element of $\theta_{k}$, such that a sufficient set of conditions for no causality is given by,

$$
\begin{aligned}
& \sum_{k=1}^{p} \theta_{k, 12} \cos (k \omega)=0 \\
& \sum_{k=1}^{p} \theta_{k, 12} \sin (k \omega)=0
\end{aligned}
$$

The null hypothesis of no causality for frequency $\omega$ is tested using a standard F-test for the linear restrictions on the coefficient of the first equation of the VAR model. The F-test follows an $F(2, T-2 p)$ distribution for every $\omega$ between 0 and $\pi$, with $T$ being the length of the time series.

This test proposed by Breitung and Candelon (2006) is straightforward to implement and has good power and size properties. Several researchers applied this methodology to study frequency domain causality (Assenmacher-Wesche et al. 2007, 2008a, b; Bodart and Candelon 2009; Gronwald 2009; Ciner 2011a, b; Fromentin and Tadjeddine 2020).

\section{Data}

In this paper, we have used IIP use-based data from 1994Q4 to 2019Q3 and IIP sectoral data from 2004Q2 to 2019Q3 ${ }^{8}$, from the Ministry of Statistics and Programme Implementation (MOSPI), India. The IIP sectoral data for India is available for 2-digit industries, and the IIP use-based data is classified in 5 broad categories - basic industries, capital goods industries, intermediate goods industries, consumer durables and consumer non-durables. For the first part of our paper concerning the cyclical pattern of industrial cycles, disaggregated data is necessary, and thus, we have used the most disaggregated data available for India, IIP 2-digit sectoral data. For tractability, IIP use-based

\footnotetext{
${ }^{8}$ This is done due to data limitation of sectoral IIP.
} 
data has been used in the next part of our paper concerning the relation of industrial cycles with policy parameters. Although the same can be done using IIP sectoral data, we keep it as an area for future study.

The IIP sectoral data follows NIC 2004 classification code for the base year 2004-05 and NIC 2008 classification code for the base year 2011-12. Concordance has been done for the industries to NIC 2004 classification, and wherever necessary, we have taken a weighted average of two (or more) industries to concord ${ }^{9}$. Policy variables, namely, exchange rate (INR/USD), M0, M1, M3, 91 days government securities (primary), 10 years Govt. securities yield, consumer price index, wholesale price index have been taken from the Reserve Bank of India's Database of Indian Economy (DBIE).

All the variables have been deseasonalized using Census X-13 ARIMA-SEATS seasonal adjustment program. All the variables are stationary at the first difference.

We have constructed realized real interest rate (RRIR) as follows:

$$
\begin{aligned}
& \operatorname{RRIR}(\text { Non - consumer industries }) \\
& \quad=(G-\operatorname{secs} 10 \text { years yield })_{-1}-W P I(\text { manufacturing }) \text { inflation }
\end{aligned}
$$

$R R I R($ Consumer industries $)=(G-\text { secs } 10 \text { years yield })_{-1}-C P I$ inflation

While reserve money M0 proxies currency whose use dominates parts of the Indian economy, M1 proxies demand deposits used for working capital, M3 is close to aggregate credit, and the 91 days government securities is the risk-free short-run nominal interest rate. Two RRIRs are obtained. First, we subtract next period wholesale price inflation from the long-run government securities rate. Second, we subtract CPI inflation from it. The relevant product real interest rate for an industry requires subtracting inflation in the product it produces from the nominal rate. In the absence of such detailed price data, we use CPI for consumer goods industries and WPI, which is closest to producer prices, for the others.

We classify the 2-digit industries into their respective usage-based categories using the maximum weight method (Table 1A, appendix). NIC 17 (Textiles), NIC 20 (Wood \& Products of Wood \& Cork except Furniture, Articles of Straw \& Plating Materials), NIC 21 (Paper \& Paper Products), NIC 25 (Rubber \& Plastic Products) and, NIC 28 (Fabricated Metal Products except Machinery \& Equipment) is classified into intermediates. Basic goods consist of NIC 23 (Coke, Refined Petroleum Products \& Nuclear Fuel), NIC 26 (Other Non-Metallic Mineral Products) and NIC 27 (Basic Metals). NIC 29 (Machinery and Equipment nec), NIC 34 (Motor Vehicles, Trailers, Semi-trailers), NIC 30 (Computer, electronic and optical products) and NIC 31 (Electrical Machinery \& Apparatus nec) is classified as capital goods industries. NIC 36 (Furniture Manufacturing nec) and

\footnotetext{
${ }^{9}$ We have not taken the previous IIP series (base year 1994-95) because it follows NIC 1987 and the concordance lead to a significant aggregation of different industries.
} 
NIC 35 (Other Transport Equipment) consists of consumer (C) durables. NIC 15 (Food Products \& Beverages), NIC 16 (Tobacco Products), NIC 18 (Wearing Apparel, Dressing and Dyeing of Fur), NIC 19 (Luggage, Handbags, Saddlery, Harness \& Footwear, Tanning \& Dressing of Leather Products), NIC 22 (Publishing, Printing \& Reproduction of Recorded Media) and, NIC 24 (Chemicals \& Chemical Products) is classified into consumer (C) nondurables. Electricity and mining are considered as Basic goods.

\section{Result}

Using deseasonalized data, we checked stationarity and normality of the cycles and did suitable modifications ${ }^{10}$ wherever required. The cyclical component was extracted using the HP filter and the CF filter. We find that the aggregate IIP shows a 4-year cycle duration irrespective of the filter chosen (Table 2A, appendix). The average duration of a HP filtered cycle in the individual series is around 5 years whereas the maximum duration has been observed in "Mining" and "Rubber \& Plastic products" industries (7.5 years). It has also been observed that "C durables" exhibit the highest average duration ( 7.5 years) whereas " $\mathrm{C}$ non-durables" exhibit the shortest duration (4.67 years). Our result is robust even when we consider CF filtered cycles. In the literature, it has been observed that a typical business cycle in India has a duration of 5 years whereas we find that the industrial cycles have very diverse durations, ranging from 3 years to 7.5 years. Capital goods and $\mathrm{C}$ durables tend to have longer cycles.

We have also carried out cyclicality tests of sectoral industrial cycles with respect to aggregate IIP series. Table 3A (appendix) shows the correlation coefficient along with 10\% significance level. We find that only "Tobacco products" industry is countercyclical with the aggregate IIP series. Highest procyclicality is observed in "Machinery and Equipment nec" and the result is same if we consider CF filtered cycles. Most industries are pro-cyclical, while a few, largely $\mathrm{C}$ non-durables are acyclical, only one is countercyclical.

The dynamic correlation along with the lags (leads) has been given in Table 4A (appendix), both for HP filtered and CF filtered cycles. For example, "Other Non-Metallic Mineral Products" is a coincident industry with the aggregate IIP series because we observe the highest correlation at lag $=0$. Here we observe that there is a high variation of leading/lagging industry even within the usage group, but there is a higher concentration of lead and coincident industries among basic and capital goods.

\subsection{Industrial Cycles Dating}

Since India, following the liberalization episodes of the 1990s has not had any actual fall in output levels. Hence, the classical approach is not appropriate for the identification of cyclical turning

\footnotetext{
${ }^{10}$ All the series were stationary at the first difference.
} 
points (Pandey et al. 2017). Boschan and Banerji (1990) pointed out that growth-cycle approach is more appropriate when the identification of business cycle dates is desired. So, here we have applied the dating algorithm on the cycles generated by the HP filter ${ }^{11}$ on the levels of the IIP series.

$$
\text { IIP level form } \stackrel{\text { Hodrick-Prescott Filter }}{\longrightarrow} \text { IIP cycles } \stackrel{\text { Harding-Pagan Algorithm }}{\longrightarrow} \text { Turning points }
$$

Table 1 reports the summary statistics for cyclical durations (peak to peak for recessions and trough to trough for expansions) based on usage of the sectors. We find that the average cyclical duration of the aggregate IIP series is 7 quarters during expansion and 5 quarters during recession. We also observe that the average duration of cycles during expansion takes longer than during recessions, except $\mathrm{C}$ goods. It can also be observed from the duration asymmetry (Table 2), which is basically the ratio of cyclical duration during expansion to that during recession. We find that the industries show varying duration asymmetry with "Intermediate" and "Capital" industry groups showing the higher duration asymmetry than aggregate IIP. For "Intermediate" an expansion in this group can take about 1.49 times more than during recessions. The "C durables", on an average, exhibit the lowest duration asymmetry.

\begin{tabular}{|l|r|r|r|r|r|r|r|r|}
\hline \multirow{2}{*}{ Cycle Durations } & \multicolumn{2}{|c|}{ Mean } & \multicolumn{2}{|c|}{ Maximum } & \multicolumn{2}{c|}{ Minimum } & \multicolumn{2}{c|}{ SD } \\
\cline { 2 - 9 } & Expansion & Recession & Expansion & Recession & Expansion & Recession & Expansion & Recession \\
\hline Basic & 5 & 5.45 & 10 & 12 & 2 & 2 & 2.36 & 2.94 \\
\hline Capital & 6.89 & 4.87 & 15 & 10 & 2 & 2 & 3.84 & 2.92 \\
\hline Intermediate & 6.29 & 4.55 & 12 & 9 & 2 & 2 & 2.87 & 2.37 \\
\hline C durables & 5.1 & 6.63 & 12 & 10 & 2 & 2 & 3.45 & 3.38 \\
\hline C non-durables & 6.46 & 6.86 & 15 & 16 & 2 & 3 & 3.43 & 3.76 \\
\hline Aggregate & 7 & 5 & 12 & 9 & 2 & 2 & 4 & 2.94 \\
\hline
\end{tabular}

Table 1: Duration of cycles (aggregate usage level) (in years)

\begin{tabular}{|l|r|r|r|r|}
\hline Duration Asymmetry & \multicolumn{1}{|c|}{ Mean } & Maximum & \multicolumn{1}{c|}{ Minimum } & \multicolumn{1}{c|}{ SD } \\
\hline Basic & 0.96 & 1.27 & 0.64 & 0.26 \\
\hline Capital & 1.43 & 1.71 & 1.24 & 0.20 \\
\hline Intermediate & 1.49 & 2.6 & 0.92 & 0.65 \\
\hline C durables & 0.79 & 1.02 & 0.56 & 0.32 \\
\hline C non-durables & 0.97 & 1.29 & 0.75 & 0.26 \\
\hline Aggregate & \multicolumn{5}{|c|}{1.4} \\
\hline
\end{tabular}

Table 2: Duration Asymmetry (aggregate usage level)

Now, we shift our focus to the number of cycles observed by the industries during our period of study (Table 3 and 4). We observe that "Durables" and "Basic" shows more frequent phase shift

\footnotetext{
${ }^{11}$ We have also applied the same technique on CF cycle, and it will be made available on request. It shows the robustness of our findings.
} 
both during recessions (Table 6) and whereas during expansions (Table 7) most phase shift happens in "Basic". "Non-durables" exhibit the lowest number of phase shifts both during expansions and recessions.

\begin{tabular}{|l|r|r|r|r|}
\hline \multicolumn{1}{|c|}{ Recession Cycles } & \multicolumn{1}{|c|}{ Mean } & Maximum & Minimum & \multicolumn{1}{l|}{ SD } \\
\hline Basic & 5 & 7 & 3 & 1.58 \\
\hline Capital & 4.75 & 6 & 4 & 0.96 \\
\hline Intermediate & 4.8 & 6 & 4 & 0.84 \\
\hline Durables & 5 & 6 & 4 & 1.41 \\
\hline Non-durables & 4 & 5 & 3 & 0.63 \\
\hline Aggregate & \multicolumn{4}{|c|}{5} \\
\hline
\end{tabular}

\begin{tabular}{|l|r|r|r|r|}
\hline Expansion Cycles & \multicolumn{1}{|c|}{ Mean } & Maximum & Minimum & \multicolumn{1}{l|}{ SD } \\
\hline Basic & 4.4 & 6 & 3 & 1.34 \\
\hline Capital & 3.75 & 5 & 3 & 0.96 \\
\hline Intermediate & 4 & 5 & 3 & 0.7 \\
\hline C durables & 4 & 5 & 3 & 1.41 \\
\hline C non-durables & 3.67 & 4 & 3 & 0.52 \\
\hline Aggregate Table 4: Expansion cycles (Trough to Trough)
\end{tabular}

Next, we turn our focus to amplitude of the cycles. Amplitude during expansion and recession phases of a cycle measures the extent of economic activity change during the phase. It is observed from Table 5, that the average amplitude of "Capital" goods industries is much higher than other industries as well as the aggregate IIP series. This is observed both in expansionary and recessionary phases. The lowest average amplitude is observed in "Basic" industries during both expansionary phase and recessionary phase. Industries such as capital goods and consumer goods that have the most amplitude tend to have the least asymmetry.

\begin{tabular}{|l|r|r|r|r|r|r|r|r|}
\hline \multirow{2}{*}{ Amplitude } & \multicolumn{2}{|c|}{ Mean } & \multicolumn{2}{c|}{ Maximum } & \multicolumn{2}{c|}{ Minimum } & \multicolumn{2}{c|}{ SD } \\
\cline { 2 - 10 } & Expansion & Recession & Expansion & Recession & Expansion & Recession & Expansion & Recession \\
\hline Basic & 10.18 & 10.14 & 25.6 & 23.2 & 2.7 & 2.3 & 6.67 & 6.71 \\
\hline Capital & 104.65 & 104.98 & 341.9 & 321.5 & 21 & 6 & 101.52 & 115.43 \\
\hline Intermediate & 14.35 & 14.54 & 45.6 & 31.9 & 3.6 & 4.4 & 9.3 & 8.19 \\
\hline C durables & 40.17 & 20.24 & 72 & 54.5 & 11.5 & 31.7 & 22.57 & 8.57 \\
\hline C non-durables & 20.47 & 22.85 & 85.4 & 75.9 & 5.1 & 3.1 & 18.42 & 17.56 \\
\hline Aggregate & 10.64 & 10.03 & 17.9 & 19 & 2.6 & 1.8 & 6.64 & 7.21 \\
\hline
\end{tabular}




\subsection{Co-movement and phase-shifts}

\subsubsection{Concordance and diffusion index}

Despite the differences in the duration properties, using the disaggregated individual industries cycle, we find that phase shifts tend to coincide across industries. To quantify the degree of concentration of cyclical phases, we adopt two measures of co-movement, diffusion and concordance indices, in the spirit of Chang and Hwang (2015).

From Table 6, we find a high degree of concordance across industries ranging from 0.66 to 0.49 , with a mean of 0.59 , suggesting that a randomly chosen pair of industries are in the same cyclical phase about $59 \%$ of the time. The concordance index with the aggregate IIP series also averages 0.65 .

\begin{tabular}{|l|r|c|c|}
\hline & Mean & Maximum & Minimum \\
\hline Pairwise & 0.59 & 0.66 & 0.49 \\
\hline Aggregate & \multicolumn{3}{|c|}{0.65} \\
\hline \multicolumn{4}{|c|}{ Table 6: Concordance Index }
\end{tabular}

Table 7 reports the summary of the diffusion index and Figure 2 displays the diffusion index over time. In the Figure, shaded bars represent recessionary phases in aggregate IIP growth cycles. Table 8 lists turning points for the same ${ }^{12}$. We report the diffusion index in the contractionary phase. This index measures how widely contractions are spread in the industries. It is observed the fraction of industries experiencing a recession rises sharply during every IIP recession, whereas it remains very low during IIP expansions. During aggregate IIP recessions, the average fraction of industries in recession is $45 \%$ whereas, during IIP expansions, the fraction is only $28 \%$.

Taking both indices together, confirms the co-movement of industries is a salient feature of the Indian economy. Co-movement is also observed in the U.S. context (Chang and Hwang, 2015).

\begin{tabular}{|l|r|r|r|r|}
\hline & \multicolumn{1}{|c|}{ Mean } & Maximum & Minimum & \multicolumn{1}{l|}{ SD } \\
\hline Overall & 0.32 & 0.64 & 0 & 0.17 \\
\hline IIP Recession & 0.45 & 0.64 & 0.27 & 0.15 \\
\hline IIP Expansion & 0.28 & 0.64 & 0 & 0.16 \\
\hline \multicolumn{7}{|c|}{ Table 7: Diffusion Index }
\end{tabular}

\footnotetext{
${ }^{12}$ Table 6A (Appendix) lists the turning points of aggregate IIP series at the level form.
} 


\section{Diffusion Index}

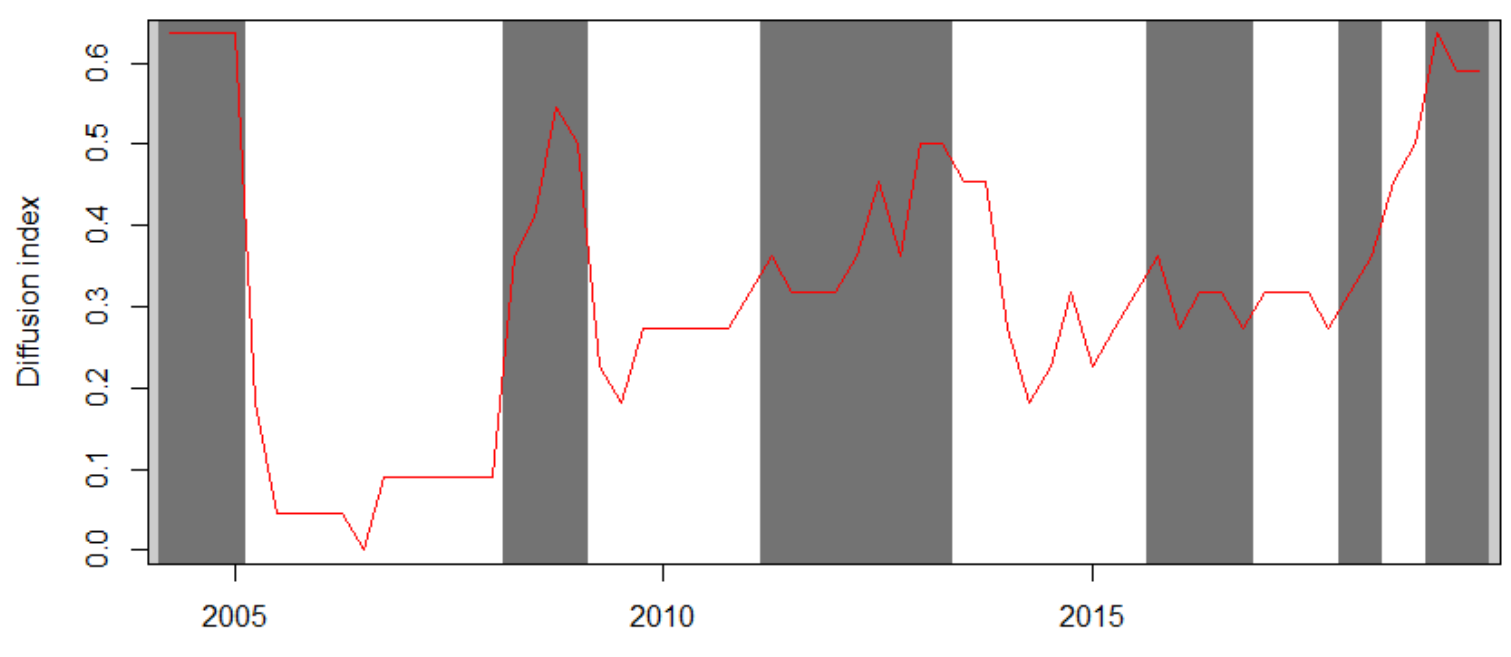

Quarters

Figure 2: Diffusion index (over time)

\begin{tabular}{|l|l|l|l|l|}
\hline \multicolumn{7}{|c|}{ Aggregate IIP Series } \\
\hline Start Date & End Date & Phase & Duration (in quarters) & Amplitude \\
\hline- & 2005 Q1 & Recession & & \\
\hline 2005 Q1 & 2008 Q1 & Expansion & 12 & 17.9 \\
\hline 2008 Q1 & 2009 Q1 & Recession & 4 & 19 \\
\hline 2009 Q1 & 2011 Q1 & Expansion & 8 & 16.8 \\
\hline 2011 Q1 & 2013 Q4 & Recession & 9 & 11.6 \\
\hline 2013 Q2 & 2015 Q3 & Expansion & 9 & 6.1 \\
\hline 2015 Q3 & 2016 Q4 & Recession & 5 & 7.7 \\
\hline 2016 Q4 & 2017 Q4 & Expansion & 4 & 9.8 \\
\hline 2017 Q4 & 2018 Q2 & Recession & 2 & 1.8 \\
\hline 2018 Q2 & 2018 Q4 & Expansion & 2 & 2.6 \\
\hline 2018 Q4 & - & Recession & & \\
\hline
\end{tabular}

\subsubsection{Distribution of turning points}

From Table 9, we find that there is a 56\% chance of a leading industry in current IIP peak to be a leading industry in the next IIP peak, whereas $44 \%$ chance of a leading industry becoming a lagging industry. We observe that the probability for an industry to be in the leading phase drops as

\footnotetext{
${ }^{13}$ Turning points of disaggregated industrial cycles and aggregate IIP cycles has been given in Table 5A and 6A (appendix).
} 
we compare P2P (peak to peak) with T2T (trough to trough). More generally, we observe that the probability of an industry remaining in the same phase drops as we go from P2P to T2T.

We have used a lead/lag of 8 quarters following Harding and Pagan (2006). If there is a conflict of phase change, i.e., if an industry has multiple peaks or troughs in 8 quarters before/after the aggregate IIP peak or trough, we have used the minimum distance algorithm. If an industry has a peak at 4 lag and at -1 lag, we have taken the -1 lag and termed the industry as a leading industry.

\begin{tabular}{|c|c|c|c|c|c|c|}
\hline & & \multicolumn{5}{|c|}{ Previous } \\
\hline & & & Leading & Lagging & Coincident & Acyclical \\
\hline \multirow{4}{*}{$\mathbf{P 2 P}$} & \multirow{8}{*}{$\underset{\Xi}{\vec{\Xi}}$} & Leading & 0.56 & 0.44 & 0.22 & 0.00 \\
\hline & & Lagging & 0.75 & 0.25 & 0.00 & 0.00 \\
\hline & & Coincident & 0.29 & 0.43 & 0.00 & 0.29 \\
\hline & & Acyclical & 0.40 & 0.20 & 0.20 & 0.20 \\
\hline \multirow{4}{*}{$\mathbf{T 2 T}$} & & Leading & 0.29 & 0.43 & 0.00 & 0.29 \\
\hline & & Lagging & 0.40 & 0.20 & 0.00 & 0.40 \\
\hline & & Coincident & 0.43 & 0.57 & 0.00 & 0.00 \\
\hline & & Acyclical & 0.29 & 0.57 & 0.00 & 0.14 \\
\hline
\end{tabular}

Figure 3 displays the concentration asymmetry of the industries. We observe not much sharp contrast between the shapes of peak and trough clusters across the aggregate IIP lags, with the maximum reached at lag $=0$. IIP sectoral peaks are more concentrated in the leads from the aggregate IIP lead date than the troughs. The sectoral troughs are more or less dispersed in the leads and the lags of the aggregate IIP series. Table 5A (appendix) shows less concentration of peaks and troughs after 2011, suggesting some industries continued to do well during the slowdown.

Upon closer inspection of Figure 3, we find that, for troughs, $27 \%$ of the industries on average exit simultaneously from the contraction phase at the aggregate IIP trough date. Second, peak clusters are skewed toward lags (of the aggregate IIP Series), whereas trough clusters tend to be uniform. For peaks, about $28 \%$ of industries newly enter the contraction phase at the aggregate IIP peak date. For peaks, the sums of the industry fractions over the left and right sides of the cluster are $34 \%$ and $59 \%$. In trough clusters, the respective ratios are $42 \%$ and $41 \%$. 


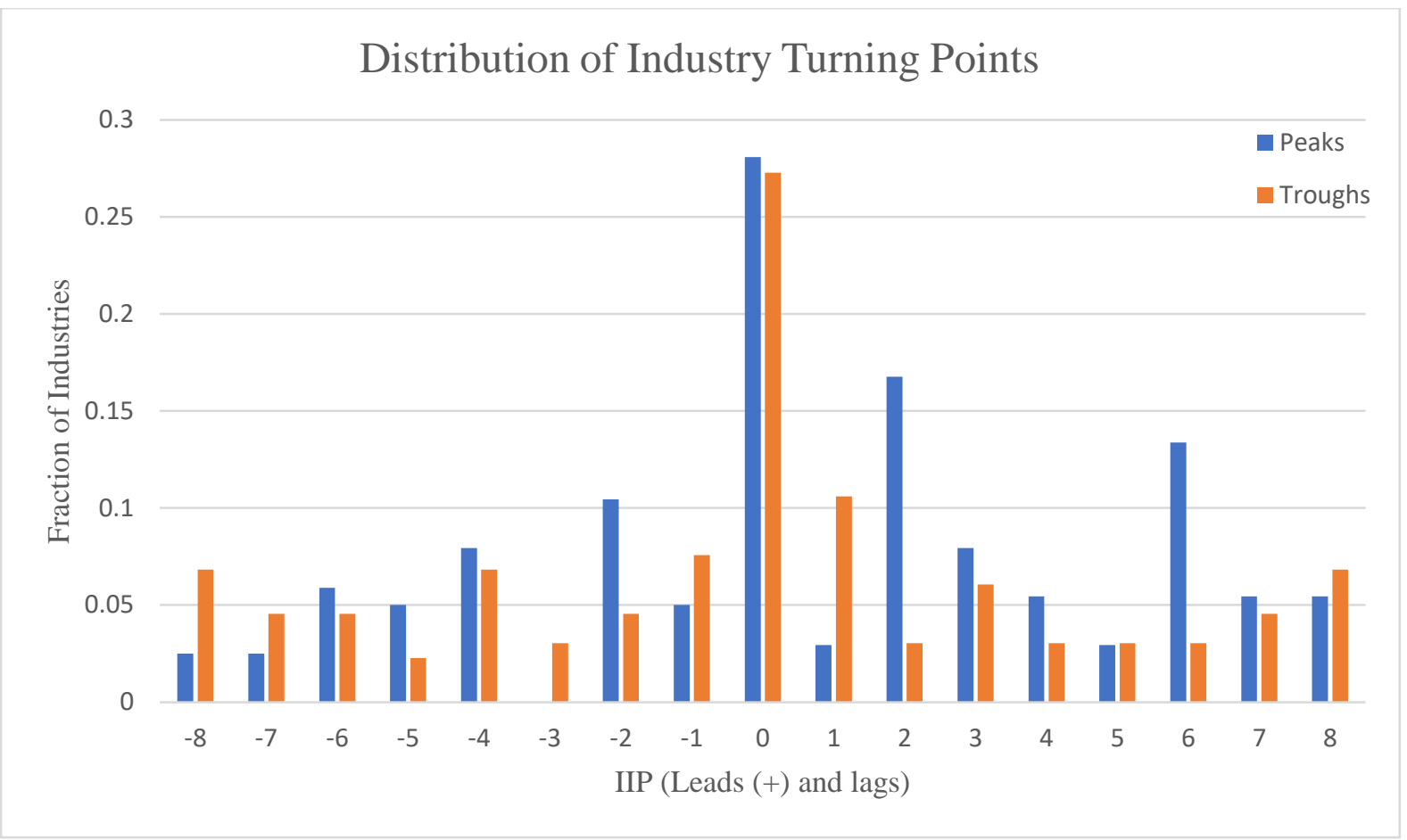

Figure 3: Turning points asymmetry

\subsection{Causality}

In this section, we present the result of the causality test. We have followed Diebold (2001) and Lemmens et al. (2008) and used the following condition as lag length: $M=\sqrt{T}$ where $T$ is the length of the series. In our paper $M=10$. The frequency $(\omega)$ in the horizontal axis can be translated into a cycle of $T=\frac{2 \pi}{\omega}$ quarters. The green line in the graphs denotes $10 \%$ significance level, and the red line denotes $5 \%$ significance level.

We have used the logarithmic form to examine relationships between IIP growth rate series and exchange rate, M0, M1 and M3. The former has been taken due to the convention regarding usage of the exchange rate in logarithmic form. The logarithmic form is used to bypass the problem of singularity. The level form is used in other relations.

\subsubsection{Exchange rate}

From Figure 4, we observe that there is evidence of significant causality from exchange rate to basic goods (IIP1) in high frequencies indicating long run cycles whereas there is evidence of reverse causality in lower frequencies indicating short run cycles. There is evidence of medium run cycles from exchange rate to capital goods (IIP2) but no significant reverse causality. For intermediate goods (IIP3), there is evidence of both short run and medium run cycles to exchange rate but no evidence of cycles from the exchange rate to the growth rate of intermediate goods cycle. It is also 
striking to find evidence of no significant causality from exchange rate to consumer goods (neither for consumer durables nor consumer non-durables). These results indicate some appreciation may help India's investment cycle since capital goods have a large import content.
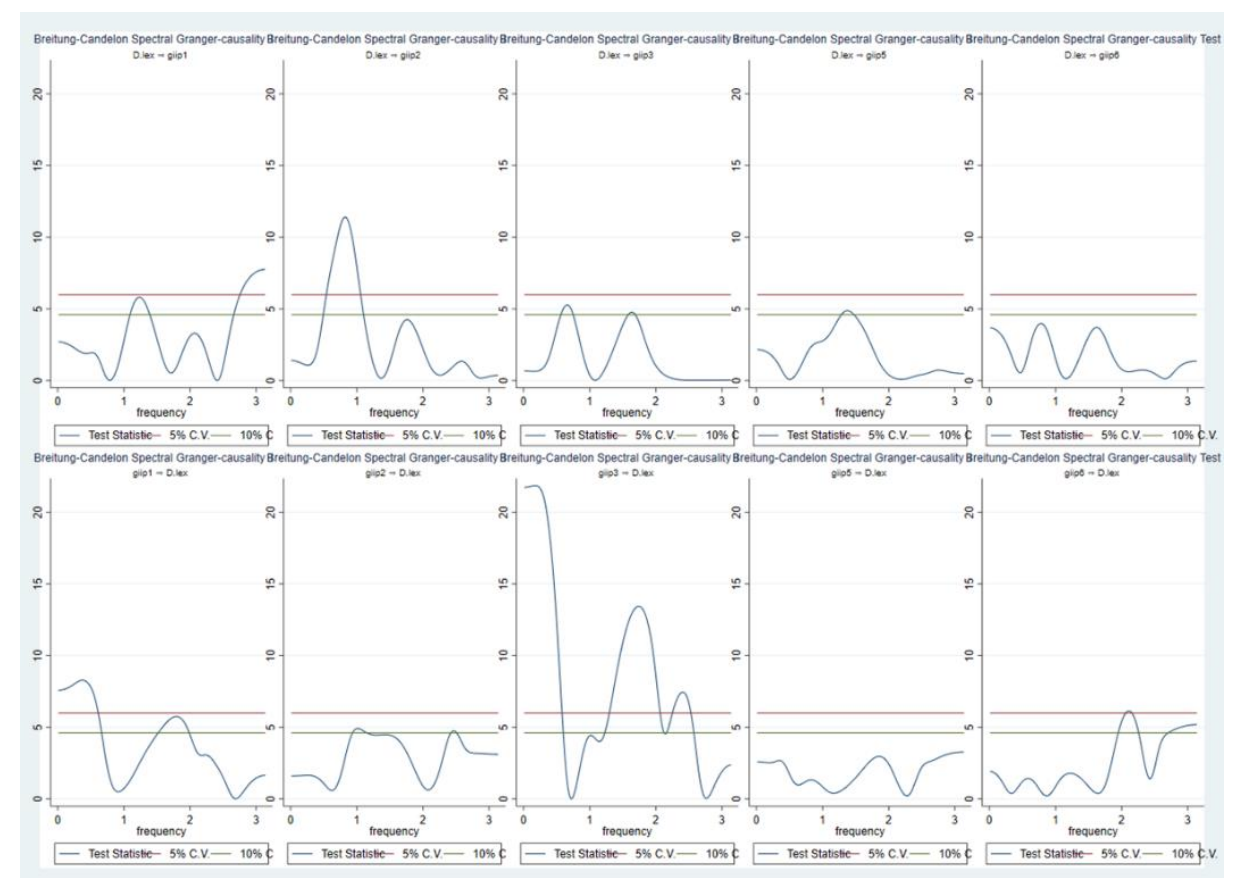

Figure 4: Exchange rate causality

\subsubsection{MO}

From Figure 5, it is evident that there is significant causality from M0 to intermediate growth rates (at medium frequencies) and consumer non-durables (at higher frequencies) yielding medium run and long run cycles, respectively.

Reverse causality is present from basic, capital and consumer non-durable goods growth rates to M0 at low frequencies whereas, both medium run and long run cycles are generated for consumer durables growth rate to M0. 


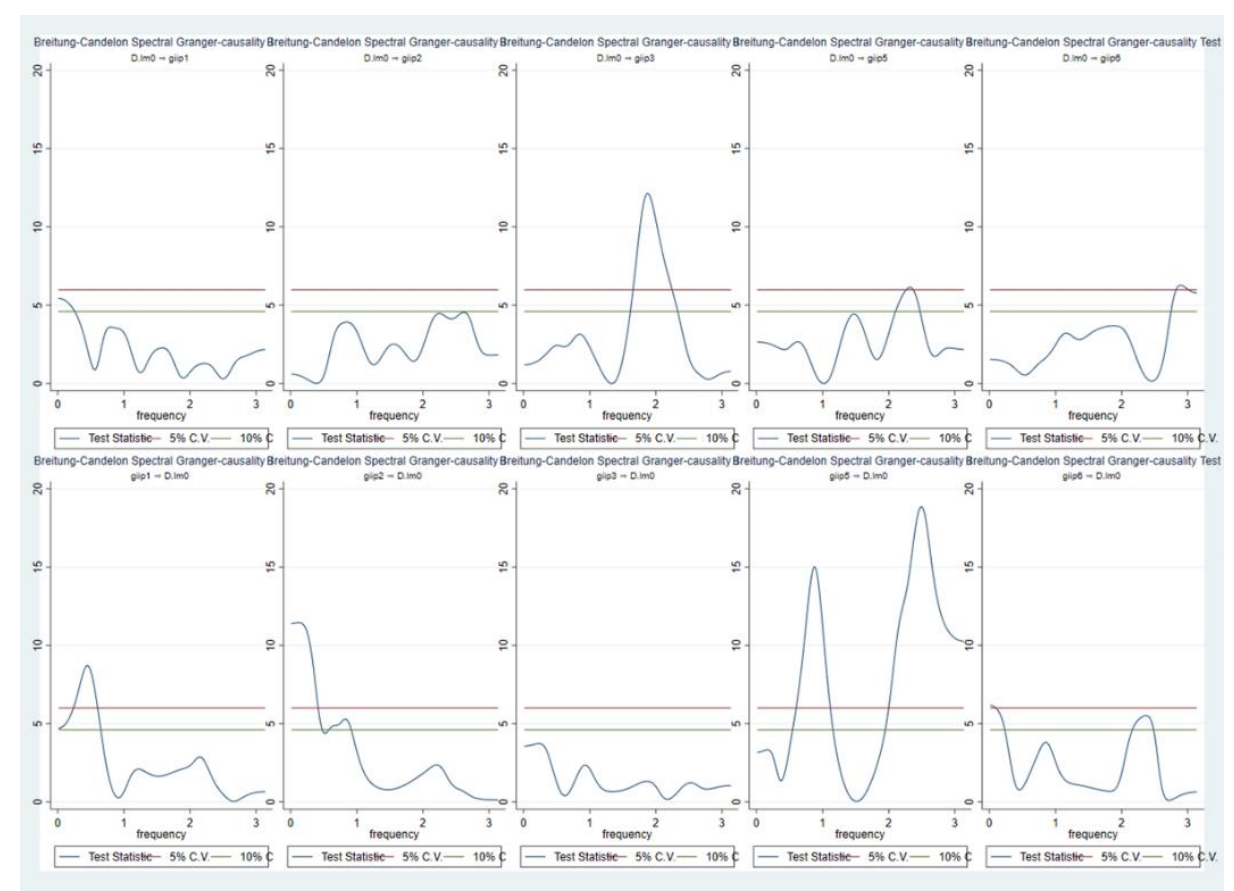

Figure 5: M0 Causality

\subsubsection{M1}
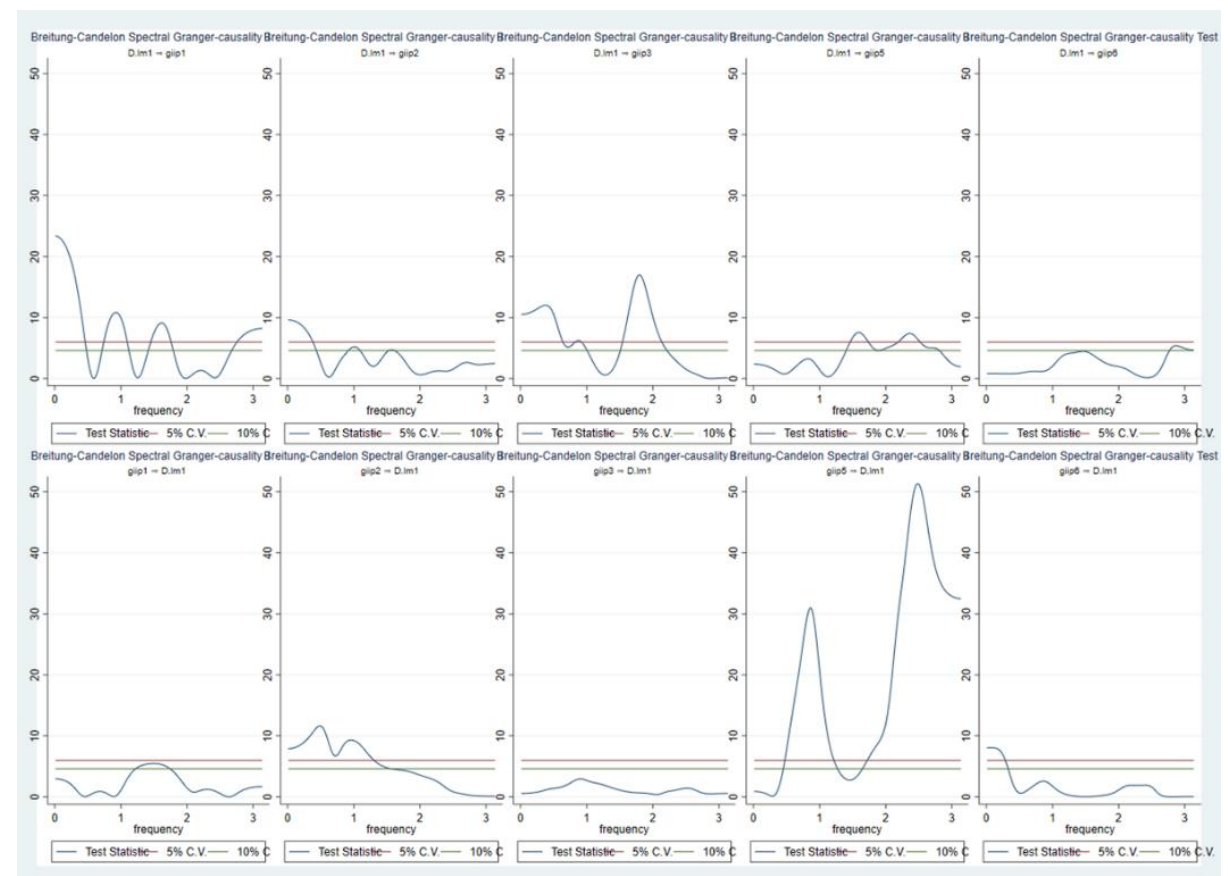

Figure 6: M1 causality

From Figure 6, we observe that M1 causes basic, capital, and intermediate growth rates in low frequencies and medium frequencies whereas for consumer durables, M1 causes medium run cycles. Reverse causality is observed with respect to capital (short to medium run cycles), consumer durables (medium to long run cycles) and consumer non-durables (short run cycles). 


\subsubsection{M3}

There is evidence of short run and medium run cycles from M3 to intermediate growth rate cycles whereas long run cycles are observed for consumer goods growth rate cycles. Reverse causality is present for intermediate and consumer durables (at medium frequencies) and consumer nondurables (at low frequencies).

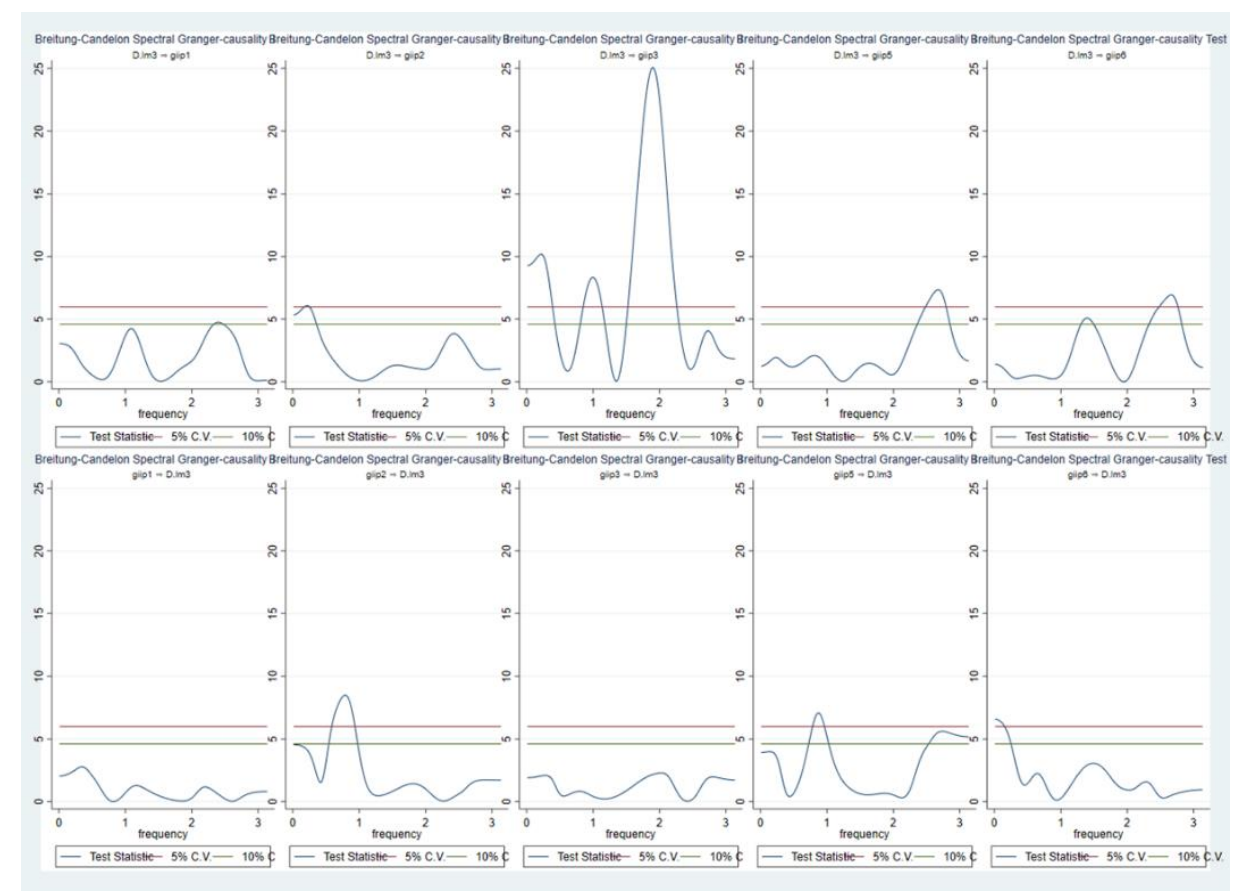

Figure 7: M3 causality

\subsubsection{1 days Government securities yield (primary)}

Govt. securities yield as the risk-free nominal interest rate is causing capital goods growth rate cycles (at medium and high frequencies) whereas reverse causality occurs at medium frequencies. Causality runs from intermediate growth rate to govt. securities yield at short run and long run cycles. Results are contrasting for consumer goods. Uni-directional causality runs from govt. securities yield cycle to consumer durables (at high frequencies) whereas the causality runs from consumer nondurables to govt. securities rate (at medium frequencies). 


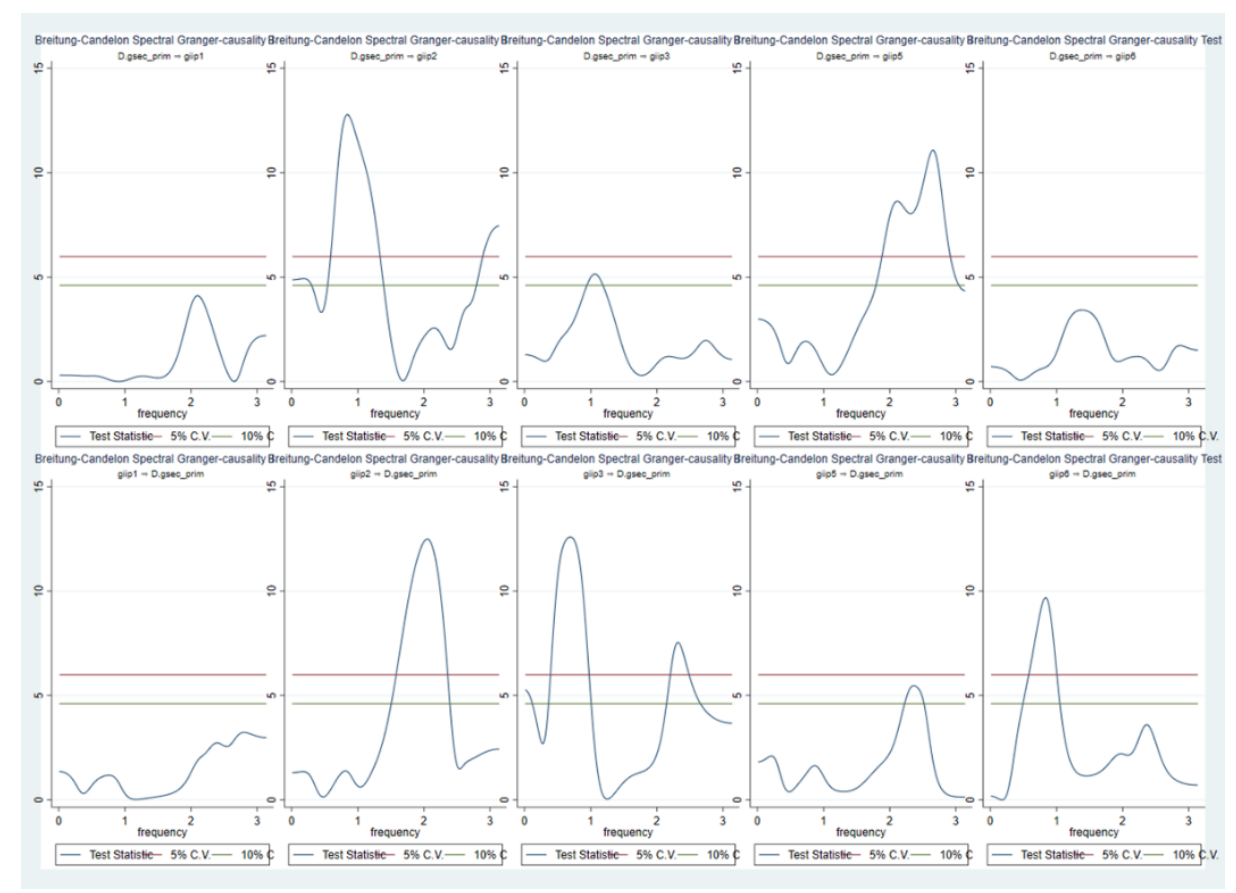

Figure 8: Govt. Sec. yield causality

\subsubsection{Realized real interest rate (RRIR)}

From Figure 9, we observe that, RRIR significantly causes intermediate growth rate cycles (at medium frequencies) and consumer non-durables (at low frequencies) yielding medium run and short run cycles. However, reverse causality is only for consumer durables causing medium run cycles (of RRIR).

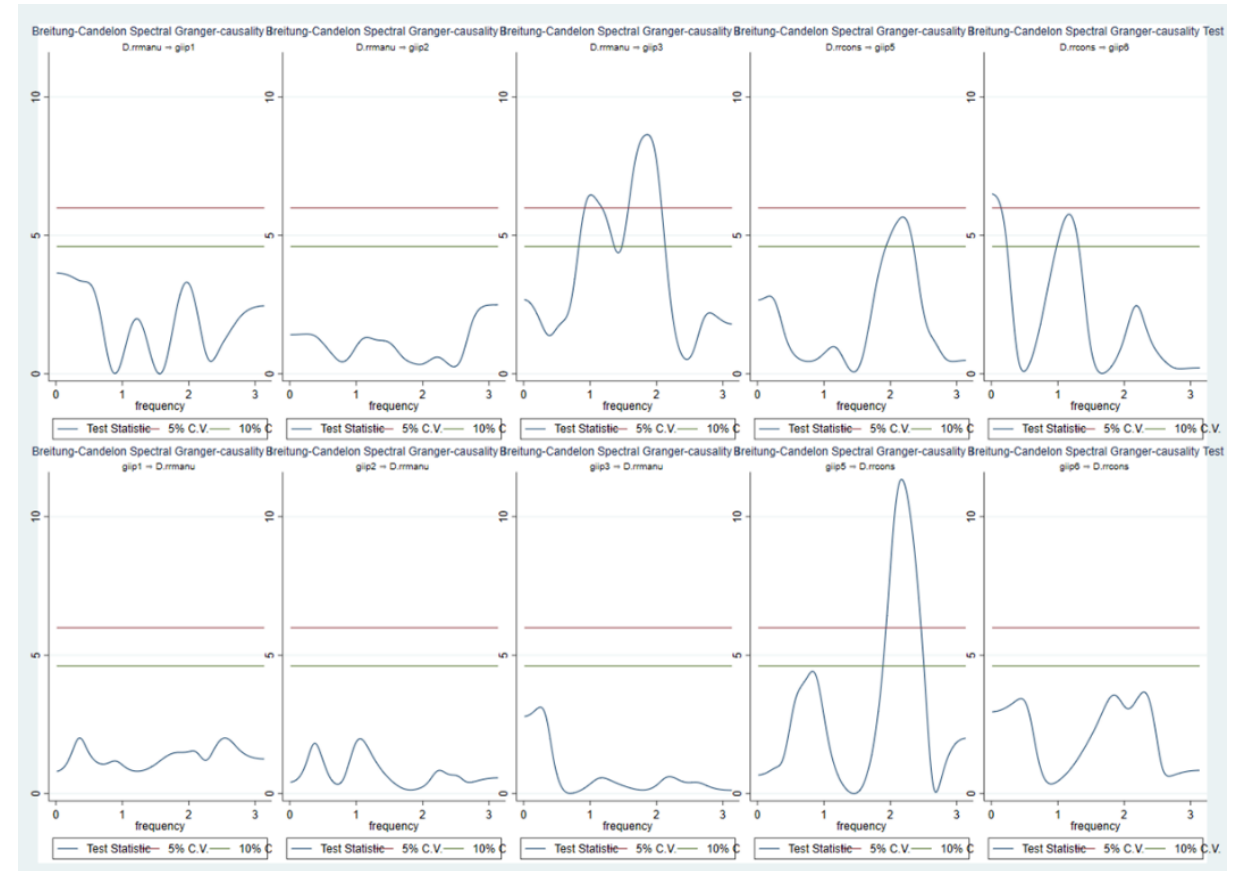

Figure 9: RRIR causality 


\subsubsection{Government Consumption}

Unidirectional causality runs from government consumption to basic goods (at medium frequencies) and from intermediate growth rates and consumer durables to government consumption yielding long run and medium run cycles.

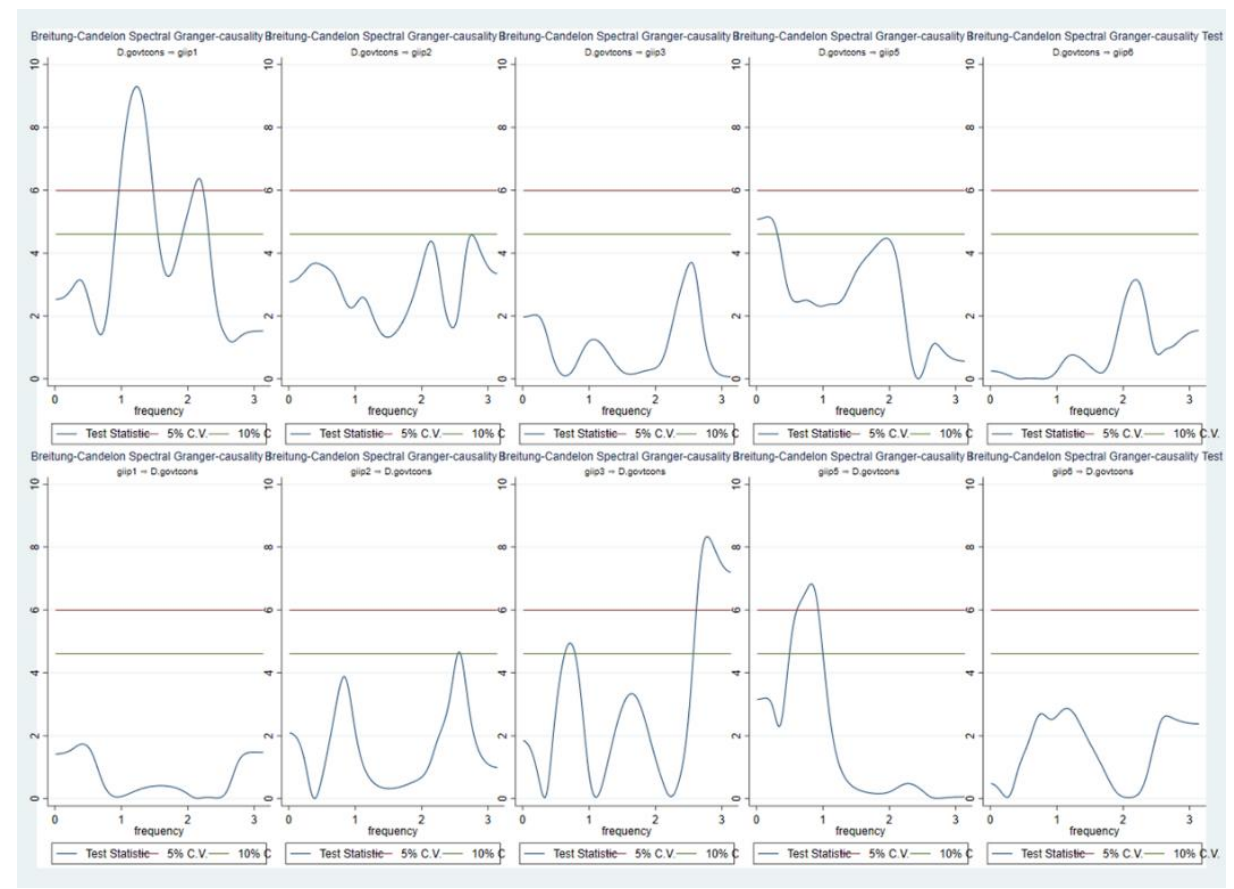

Figure10: Government consumption causality

\section{Conclusion}

Details of industry business cycles obtained will be useful for policymakers who want to influence them, analysts who want to predict, and researchers who want to understand them. Analysis of industry phase shifts gives more insights and is more robust than the aggregate correlations largely available in the earlier literature on developing economy business cycles.

The analysis establishes that business cycles do exist in India, and are even more pronounced for industry. It is important to make this point because the Indian debate tends to be dominated by growth, development and structural reform. The level of co-movement across disaggregated industry points to some common drivers. As most industry cycles are pro-cyclical counter-cyclical policy becomes all the more important. Causality analysis by industry type shows the impact of many macroeconomic variables. The diversity of the impact points to aspects of Indian macroeconomic structure. Therefore, stabilization policies need to be used more and fine-tuned based on research.

For example, since capital goods are a lead industry and are sensitive to the policy interest rate, timely rate changes are important. Exchange rates also affect their cycles. Another lead sector is 
basic goods. Here investment by public sector enterprises has a role to play. Expansions are longer for basic goods and they are relatively independent to monetary policy shocks and affected by government expenditure pointing to their stabilizing function. Currency and credit matter for consumer non-durables indicating the importance of maintaining liquidity. Interest rates also affect consumer durables, countering the myth that interest rates do not matter for demand and output because of poor transmission and other issues. They do matter but in combination with currency and credit.

There are specific results on the duration of individual industry cycles, their cyclicality, phase shifts, amplitude, lead-coincident sectors, duration symmetry and co-movement. Since co-movement is greater during troughs, a broad-based upturn is possible in suitable conditions. The exchange rate, currency, credit, nominal and real interest rates all affect industry cycles, but differences in impact by industry type may be due to the structure of the economy with its mix of formal and informal sectors. There is also reverse causality from industry cycles to monetary policy variables. "Cash and credit" is more important for consumer non-durables, while interest rates matter for consumer durables and capital goods. Basic goods are somewhat insulated, except for working capital, perhaps because of more government ownership. The scattered pattern of peaks and troughs after 2013, suggests some industries continued to do well during the post 2011 growth slowdown. Industrial cycles during this period were shallow and short.

Future work includes using more disaggregated industry data. Relatively weak results with RRIR suggest it needs to be calculated using more disaggregated product price series. Causality with other macroeconomic series such as oil price inflation can also be explored. 


\section{References}

Artis, M., Marcellino, M., \& Proietti, T. (2004). Dating Business Cycles: A Methodological Contribution with an Application to the Euro Area. Oxford Bulletin of Economics and Statistics. 6(4), 537-565. September.

Assenmacher-Wesche, K., \& Gerlach, S. (2007). Money at Low Frequencies. Journal of the European Economic Association. 5(2-3), 534-542.

Assenmacher-Wesche, K., \& Gerlach, S. (2008). Interpreting euro area inflation at high and low frequencies. European Economic Review. 52(6), 964-986.

Assenmacher-Wesche, K., \& Gerlach, S. (2008). Money growth, output gaps and inflation at low and high frequency: Spectral estimates for Switzerland. Journal of Economic Dynamics \& Control. Elsevier, 32(2), 411-435, February.

Baxter, M., \& King, R. G. (1999). Measuring Business Cycles: Approximate Band-pass Filters for Economic Time Series. Review of Economics and Statistics, 81(4), 575-593.

Bloom, N., Floetotto, M., Jaimovich, N., Saporta-Eksten, I., \& Terry, S. J. (2018). Really Uncertain Business Cycles. Econometrica. 86(3), 1031-1065. May.

Boschan, C., \& Banerji, A. (1990). A reassessment of composite indexes. In Analysing Modern Business Cycles: Essays Honoring Geoffrey H.Moore. New York USA.

Breitung, J., \& Candelon, B. (2006). Testing for short- and long-run causality: A frequency-domain approach. Journal of Econometrics. 132(2), 363-378.

Bry, G., \& Boschan, C. (1971). Front matter to "Cyclical Analysis of Time Series: Selected Procedures and Computer Programs". In Cyclical analysis of time series: Selected procedures and computer programs (pp. 13-2). NBER.

Burns, A. F., \& Mitchell, W. C. (1946). Measuring business cycles. New York, New York: National Bureau of Economic Research.

Chang, Y., \& Hwang, S. (2015). Asymmetric Phase Shifts in U.S. Industrial Production Cycles. Review of Economics and Statistics.

Christiano, L. J., \& Fitzgerald, T. J. (2003). The band pass filter. International Economic Review, 44(2), 435-465.

Ciner, C. (2011). Eurocurrency interest rate linkages: A frequency domain analysis. International Review of Economics \& Finance, 20(4), 498-505.

Ciner, C. (2011). Commodity prices and inflation: Testing in the frequency domain. Research in International Business and Finance, 25(3), 229-237.

Dua, P., \& Banerji, A. (2012). Business and growth rate cycles in India. Working paper no. 210. Centre for Development Economics, Delhi School of Economics.

Fromentin, V., \& Tadjeddine, Y. (2020). Cross-border workers and financial instability: a frequency domain causality analysis applied to the Luxembourg financial centre. Applied Economics Letters. Taylor \& Francis Journals, 27(4), 280-285, February.

Foerster, A. T., Sarte, P. D. G., \& Watson, M. W. (2011). Sectoral versus aggregate shocks: A structural factor analysis of industrial production. Journal of Political Economy, 119(1), 1-38.

Granger, C. W., \& Lin, J. L. (1995). Causality in the long run. Econometric theory, 530-536. 
Granger, C. W. (1980). Testing for causality: a personal viewpoint. Journal of Economic Dynamics and control, 2, 329-352.

Granger, C. W. (1969). Investigating causal relations by econometric models and cross-spectral methods. Econometrica, 424-438.

Gronwald, M. (2009). Reconsidering the macroeconomics of the oil price in Germany: testing for causality in the frequency domain. Empirical Economics. 36, 441-453

Geweke, J. (1982). Measurement of linear dependence and feedback between multiple time series. Journal of the American Statistical Association, 77(378), 304-313.

Harding, D., \& Pagan, A. (2006). Synchronization of cycles. Journal of Econometrics, 132(1), 59-79.

Harding, D., \& Pagan, A. (2002). Dissecting the cycle: a methodological investigation. Journal of Monetary Economics, 49(2), 365-381.

Hodrick, R. J., \& Prescott, E. C. (1997). Postwar US business cycles: an empirical investigation. Journal of Money, Credit, and Banking, 29(1), 1-16.

Hosoya, Y. (1991). The decomposition and measurement of the interdependency between secondorder stationary processes. Probability theory and related fields, 88(4), 429-444.

Kong, X., Dong, K., \& Zhang, L. (2019). Characteristics and determinants of asymmetric phase shifts in China's manufacturing industrial production cycles. Applied Economics. 52(22), 23662376.

Lemmens, A., Croux, C., \& Dekimpe, M. G. (2008). Measuring and testing Granger causality over the spectrum: An application to European production expectation surveys. International Journal of Forecasting, 24(3), 414-431.

Mankiw, N. G., \& Reis, R. (2003). What measure of inflation should a central bank target?. Journal of the European Economic Association, 1(5), 1058-1086.

Pandey, R., Patnaik, I., \& Shah, A. (2019). Business cycle measurement in India. In Business Cycles in BRICS (pp. 121-152). Springer, Cham.

Pandey, R., Patnaik, I., \& Shah, A. (2017). Dating business cycles in India. Indian Growth and Development Review. 10 (1), 32-6. https://doi.org/10.1108/IGDR-02-2017-0013

Rand, J., \& Tarp, F. (2002). Business cycles in developing countries: are they different?. World Development, 30(12), 2071-2088.

Reserve Bank of India. (2006). Report of Technical Advisory Group on Development of Leading Economic Indicators for Indian Economy. Mumbai: Reserve Bank of India.

Tiwari, A. K. (2012). An empirical investigation of causality between producer's price and consumer's price indices in Australia in frequency domain. Economic Modelling. 29(5), 1571-1578. DOI: 10.1016/j.econmod.2012.05.010

Tiwari, A. K. (2012). Causality between wholesale price and consumer price indices in India: An empirical investigation in the frequency domain. Indian Growth and Development Review. 5(2), 151-172. DOI: $10.1108 / 17538251211268071$

Wei, Y. (2015). The informational role of commodity prices in formulating monetary policy: A reexamination under the frequency domain. Empirical Economics, 49(2), 537-549. 
Appendix

\begin{tabular}{|c|c|c|c|c|c|}
\hline Names of industries & Basic & Capital & Intermediate & C Durables & $\begin{array}{l}\text { C Non- } \\
\text { durables }\end{array}$ \\
\hline Food Products \& Beverages & 2.14 & - & 2.65 & - & 67.97 \\
\hline Tobacco Products & - & - & - & - & 15.7 \\
\hline Textiles & - & - & 34.24 & 2.58 & 24.82 \\
\hline $\begin{array}{l}\text { Wearing Apparel, Dressing and } \\
\text { Dyeing of Fur }\end{array}$ & - & - & - & - & 27.82 \\
\hline $\begin{array}{l}\text { Luggage, Handbags, Saddlery, } \\
\text { Harness \& Footwear, Tanning \& } \\
\text { Dressing of Leather Products }\end{array}$ & - & - & 2.24 & - & 3.58 \\
\hline $\begin{array}{l}\text { Wood \& Products of Wood \& } \\
\text { Cork except Furniture, Articles of } \\
\text { Straw \& Plating Materials }\end{array}$ & - & - & 10.51 & - & - \\
\hline Paper \& Paper Products & - & - & 5.81 & - & 4.18 \\
\hline $\begin{array}{l}\text { Publishing, Printing \& } \\
\text { Reproduction of Recorded Media }\end{array}$ & - & - & - & 0.7 & 10.09 \\
\hline $\begin{array}{l}\text { Coke,Refined Petroleum Products } \\
\& \text { Nuclear Fuel }\end{array}$ & 36.07 & - & 31.09 & - & - \\
\hline Chemicals \& Chemical Products & 31.67 & - & 28.59 & 1.17 & 39.15 \\
\hline Rubber \& Plastic Products & - & 0.65 & 9.09 & 8.24 & 2.27 \\
\hline $\begin{array}{l}\text { Other Non-Metallic Mineral } \\
\text { Products }\end{array}$ & 25.18 & 7.07 & 5.82 & 5.07 & - \\
\hline Basic Metals & 111.919 & - & 1.43 & - & - \\
\hline $\begin{array}{l}\text { Fabricated Metal Products except } \\
\text { Machinery \& Equipment }\end{array}$ & 4.92 & 5.39 & 12.32 & 2.96 & 5.27 \\
\hline Machinery and Equipment nec & - & 28.37 & 4.61 & 4.66 & - \\
\hline $\begin{array}{l}\text { Computer, electronic and optical } \\
\text { products }\end{array}$ & - & 3.03 & - & 0.02 & - \\
\hline $\begin{array}{l}\text { Electrical Machinery \& } \\
\text { Apparatus nec }\end{array}$ & 0.03 & 15.76 & 1.96 & 0.03 & 2.02 \\
\hline $\begin{array}{l}\text { Motor Vehicles, Trailers, Semi- } \\
\text { trailers }\end{array}$ & - & 19.91 & 0.99 & 19.74 & - \\
\hline Other Transport Equipment & 0.17 & 5.37 & 0.09 & 12.62 & - \\
\hline Furniture Manufacturing nec & - & - & - & 20.11 & 9.86 \\
\hline
\end{tabular}

Table 1A: 2-digit NIC classification and the respective weights according to usage ${ }^{14}$

${ }^{14}$ The aggregate of the weights equal to 1000 . 


\begin{tabular}{|c|c|c|c|}
\hline Type & 2-digit IIP (2004 Q2 - 2019 Q3) & HP Filter & CF Filter \\
\hline & Aggregate IIP & 4 & 4 \\
\hline Basic & Mining & 7.5 & 5 \\
\hline \multirow[t]{2}{*}{ Basic } & Electricity & 3.75 & 3.75 \\
\hline & Manufacturing & 3.75 & 3.75 \\
\hline C non-durables & Food Products \& Beverages & 3.75 & 7.5 \\
\hline C non-durables & Tobacco Products & 5 & 5 \\
\hline Intermediate & Textiles & 3.75 & 3.75 \\
\hline C non-durables & Wearing Apparel, Dressing and Dyeing of Fur & 7.5 & 7.5 \\
\hline C non-durables & $\begin{array}{l}\text { Luggage, Handbags, Saddlery, Tanning \& Dressing of } \\
\text { Leather Products }\end{array}$ & 3.75 & 3.75 \\
\hline Intermediate & $\begin{array}{l}\text { Wood \& Products of Wood except Furniture, Articles of } \\
\text { Straw \& Plating Materials }\end{array}$ & 3.75 & 7.5 \\
\hline Intermediate & Paper \& Paper Products & 5 & 5 \\
\hline C non-durables & Publishing, Printing \& Reproduction of Recorded Media & 5 & 5 \\
\hline Basic & Coke, Refined Petroleum Products \& Nuclear Fuel & 5 & 5 \\
\hline C non-durables & Chemicals \& Chemical Products & 3 & 3.75 \\
\hline Intermediate & Rubber \& Plastic Products & 7.5 & 5 \\
\hline Basic & Other Non-Metallic Mineral Products & 3.75 & 3.75 \\
\hline Basic & Basic Metals & 3.75 & 3.75 \\
\hline Intermediate & Fabricated Metal Products except Machinery \& Equipment & 5 & 5 \\
\hline Capital & Machinery and Equipment nec. & 3.75 & 3.75 \\
\hline C durables & Furniture Manufacturing nec. & 7.5 & 2.5 \\
\hline Capital & Motor Vehicles, Trailers, Semi-trailers & 7.5 & 7.5 \\
\hline C durables & Other Transport Equipment & 7.5 & 3.75 \\
\hline Capital & Computer, electronic and optical products & 5 & 5 \\
\hline Capital & Electrical Machinery \& Apparatus nec. & 5 & 5 \\
\hline
\end{tabular}

Table 1A: Duration of the industrial cycles 


\begin{tabular}{|c|c|c|c|c|c|c|c|}
\hline & & \multicolumn{3}{|c|}{ HP Filter } & \multicolumn{3}{|c|}{ CF Filter } \\
\hline Basic & Mining & 0.43 & $*$ & Pro & 0.15 & & Acyclical \\
\hline Basic & Electricity & 0.27 & * & Pro & 0.56 & $*$ & Pro \\
\hline Basic & $\begin{array}{l}\text { Coke, Refined Petroleum Products \& } \\
\text { Nuclear Fuel }\end{array}$ & 0.25 & * & Pro & 0.43 & * & Pro \\
\hline Basic & Other Non-Metallic Mineral Products & 0.42 & $*$ & Pro & 0.53 & $*$ & Pro \\
\hline Basic & Basic Metals & 0.46 & $*$ & Pro & 0.58 & $*$ & Pro \\
\hline Capital & Machinery and Equipment nec & 0.72 & $*$ & Pro & 0.68 & $*$ & Pro \\
\hline Capital & Motor Vehicles, Trailers, Semi-trailers & 0.60 & * & Pro & 0.52 & $*$ & Pro \\
\hline Capital & $\begin{array}{l}\text { Computer, electronic and optical } \\
\text { products }\end{array}$ & 0.43 & $*$ & Pro & 0.35 & $*$ & Pro \\
\hline Capital & Electrical Machinery \& Apparatus nec & 0.32 & * & Pro & 0.23 & $*$ & Pro \\
\hline Intermediate & Textiles & 0.30 & $*$ & Pro & 0.70 & $*$ & Pro \\
\hline Intermediate & $\begin{array}{l}\text { Wood \& Products of Wood \& Cork } \\
\text { except Furniture, Articles of Straw \& } \\
\text { Plating Materials }\end{array}$ & 0.45 & * & Pro & 0.40 & * & Pro \\
\hline Intermediate & Paper \& Paper Products & 0.10 & & Acyclical & 0.14 & & Acyclical \\
\hline Intermediate & Rubber \& Plastic Products & 0.25 & $*$ & Pro & 0.01 & & Acyclical \\
\hline Intermediate & $\begin{array}{l}\text { Fabricated Metal Products except } \\
\text { Machinery \& Equipment }\end{array}$ & 0.60 & $*$ & Pro & 0.58 & $*$ & Pro \\
\hline C durables & Furniture Manufacturing nec & 0.32 & * & Pro & 0.10 & & Acyclical \\
\hline $\mathrm{C}$ durables & Other Transport Equipment & 0.37 & $*$ & Pro & 0.44 & $*$ & Pro \\
\hline C non-durables & Food Products \& Beverages & 0.54 & $*$ & Pro & 0.75 & $*$ & Pro \\
\hline C non-durables & Tobacco Products & -0.30 & $*$ & Counter & -0.34 & $*$ & Counter \\
\hline C non-durables & $\begin{array}{l}\text { Wearing Apparel, Dressing and Dyeing } \\
\text { of Fur }\end{array}$ & 0.07 & & Acyclical & 0.31 & $*$ & Pro \\
\hline C non-durables & $\begin{array}{l}\text { Luggage, Handbags, Saddlery, Harness } \\
\& \text { Footwear, Tanning \& Dressing of } \\
\text { Leather Products }\end{array}$ & 0.26 & $*$ & Pro & 0.62 & $*$ & Pro \\
\hline C non-durables & $\begin{array}{l}\text { Publishing, Printing \& Reproduction of } \\
\text { Recorded Media }\end{array}$ & 0.18 & & Acyclical & 0.41 & $*$ & Pro \\
\hline C non-durables & Chemicals \& Chemical Products & 0.36 & $*$ & Pro & 0.56 & $*$ & Pro \\
\hline
\end{tabular}

Table 2A: Classical correlation of industrial cycles (with aggregate IIP) 


\begin{tabular}{|c|c|c|c|c|c|}
\hline & & \multicolumn{2}{|c|}{ HP Cycle } & \multicolumn{2}{|r|}{ CF Cycle } \\
\hline Basic & Mining & 0 & Coincident & 13 & Lead \\
\hline Basic & Electricity & 9 & Lead & 9 & Lead \\
\hline Basic & $\begin{array}{l}\text { Coke, Refined Petroleum Products \& } \\
\text { Nuclear Fuel }\end{array}$ & 14 & Lead & 1 & Lead \\
\hline Basic & Other Non-Metallic Mineral Products & 0 & Coincident & 0 & Coincident \\
\hline Basic & Basic Metals & 9 & Lead & 10 & Lead \\
\hline Capital & Machinery and Equipment nec & 0 & Coincident & 6 & Lead \\
\hline Capital & Motor Vehicles, Trailers, Semi-trailers & 0 & Coincident & 6 & Lead \\
\hline Capital & Computer, electronic and optical products & 1 & Lead & 12 & Lead \\
\hline Capital & Electrical Machinery \& Apparatus nec & 0 & Coincident & -5 & Lag \\
\hline Intermediate & Textiles & -1 & Lag & -1 & Lag \\
\hline Intermediate & $\begin{array}{l}\text { Wood \& Products of Wood \& Cork except } \\
\text { Furniture, Articles of Straw \& Plating } \\
\text { Materials }\end{array}$ & 0 & Coincident & 2 & Lead \\
\hline Intermediate & Paper \& Paper Products & 6 & Lead & 6 & Lead \\
\hline Intermediate & Rubber \& Plastic Products & -1 & Lag & 4 & Lead \\
\hline Intermediate & $\begin{array}{l}\text { Fabricated Metal Products except } \\
\text { Machinery \& Equipment }\end{array}$ & 0 & Coincident & 7 & Lead \\
\hline $\mathrm{C}$ durables & Furniture Manufacturing nec & -11 & Lag & -11 & Lag \\
\hline C durables & Other Transport Equipment & 13 & Lead & 6 & Lead \\
\hline $\mathrm{C}$ non-durables & Food Products \& Beverages & 0 & Coincident & 0 & Coincident \\
\hline C non-durables & Tobacco Products & -1 & Lag & -1 & Lag \\
\hline C non-durables & $\begin{array}{l}\text { Wearing Apparel, Dressing and Dyeing of } \\
\text { Fur }\end{array}$ & 6 & Lead & -8 & Lag \\
\hline C non-durables & $\begin{array}{l}\text { Luggage, Handbags, Saddlery, Harness \& } \\
\text { Footwear, Tanning \& Dressing of Leather } \\
\text { Products }\end{array}$ & -7 & Lag & -8 & Lag \\
\hline C non-durables & $\begin{array}{l}\text { Publishing, Printing \& Reproduction of } \\
\text { Recorded Media }\end{array}$ & 11 & Lead & 11 & Lead \\
\hline C non-durables & Chemicals \& Chemical Products & -1 & Lag & -1 & Lag \\
\hline
\end{tabular}

Table 4A: Dynamic correlation (with aggregate IIP) (in quarters) 


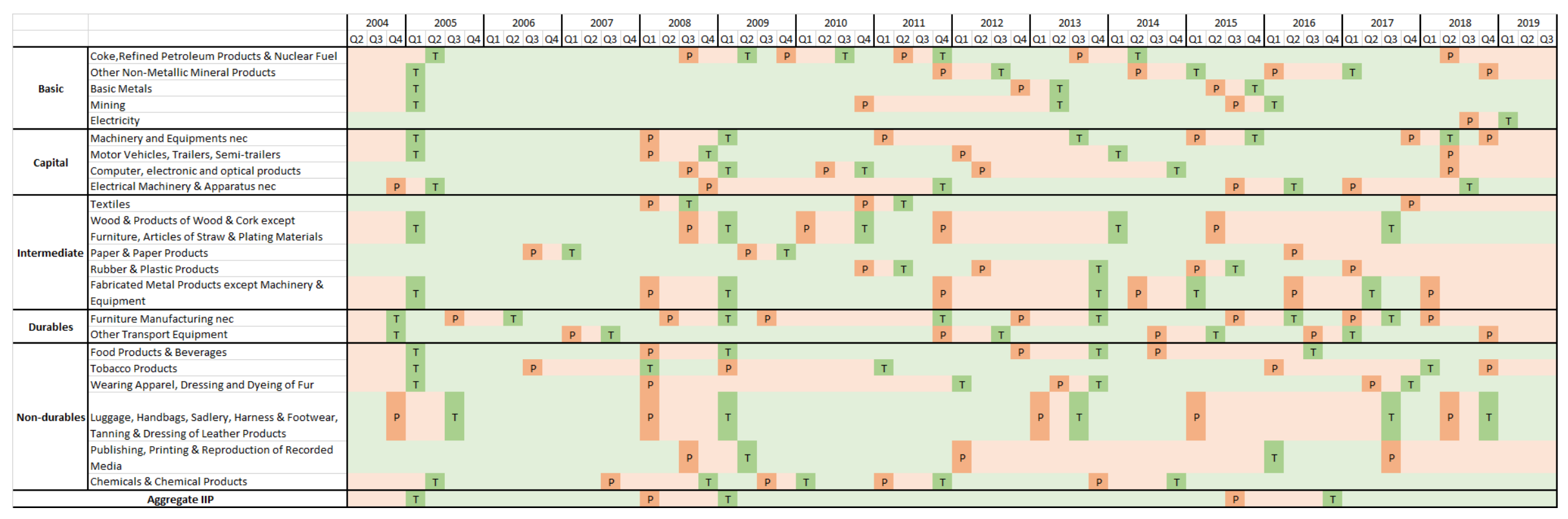

Table 5A: Peaks and troughs for each individual industry

\begin{tabular}{|l|l|l|}
\hline \multicolumn{3}{|c|}{ Aggregate IIP Series } \\
\hline Start Date & End Date & Phase \\
\hline & 2005 Q1 & Recession \\
\hline 2005 Q1 & 2008 Q1 & Expansion \\
\hline 2008 Q1 & 2009 Q1 & Recession \\
\hline 2009 Q1 & 2015 Q3 & Expansion \\
\hline 2015 Q3 & 2016 Q4 & Recession \\
\hline 2016 Q4 & & Expansion \\
\hline
\end{tabular}

Table 6A: Turning points of Aggregate IIP Series 